\title{
Article \\ A Game Theory Approach Using the TLBO Algorithm for Generation Expansion Planning by Applying Carbon Curtailment Policy
}

\author{
Seyed Hamed Jalalzad ${ }^{1}$, Hossein Yektamoghadam ${ }^{2}$, Rouzbeh Haghighi ${ }^{3}$, Majid Dehghani ${ }^{3}(\mathbb{D}$, \\ Amirhossein Nikoofard 2,*(D), Mahdi Khosravy ${ }^{4, *(D)}$ and Tomonobu Senjyu ${ }^{5}$ (D)
}

Citation: Jalalzad, S.H.;

Yektamoghadam, H.; Haghighi, R.;

Dehghani, M.; Nikoofard, A.;

Khosravy, M.; Senjyu, T. A Game Theory Approach Using the TLBO Algorithm for Generation Expansion Planning by Applying Carbon Curtailment Policy. Energies 2022, 15, 1172. https://doi.org/10.3390/ en15031172

Academic Editor: Radu-Emil Precup

Received: 30 December 2021

Accepted: 28 January 2022

Published: 5 February 2022

Publisher's Note: MDPI stays neutral with regard to jurisdictional claims in published maps and institutional affiliations.

Copyright: (C) 2022 by the authors. Licensee MDPI, Basel, Switzerland. This article is an open access article distributed under the terms and conditions of the Creative Commons Attribution (CC BY) license (https:// creativecommons.org/licenses/by/ $4.0 /)$.
1 Department of Engineering, Sardar Jangal University, Gilan 4193165-151, Iran; shjalalzad@gmail.com

2 Department of Electrical Engineering, K.N. Toosi University of Technology, Tehran 196976-4499, Iran; yektamoghadam@email.kntu.ac.ir

3 Department of Electrical Engineering, Amirkabir University of Technology, Tehran 159163-4311, Iran; rhaghighi@aut.ac.ir (R.H.); majid1369@aut.ac.ir (M.D.)

4 Cross Labs, Cross-Compass Ltd., Tokyo 104-0045, Japan

$5 \quad$ Faculty of Engineering, University of the Ryukyus, Okinawa 903-0213, Japan; b985542@tec.u-ryukyu.ac.jp

* Correspondence: a.nikoofard@kntu.ac.ir (A.N.); dr.mahdi.khosravy@ieee.org (M.K.)

\begin{abstract}
In the present climate, due to the cost of investments, pollutants of fossil fuel, and global warming, it seems rational to accept numerous potential benefits of optimal generation expansion planning. Generation expansion planning by regarding these goals and providing the best plan for the future of the power plants reinforces the idea that plants are capable of generating electricity in environmentally friendly circumstances, particularly by reducing greenhouse gas production. This paper has applied a teaching-learning-based optimization algorithm to provide an optimal strategy for power plants and the proposed algorithm has been compared with other optimization methods. Then the game theory approach is implemented to make a competitive situation among power plants. A combined algorithm has been developed to reach the Nash equilibrium point. Moreover, the government role has been considered in order to reduce carbon emission and achieve the green earth policies. Three scenarios have been regarded to evaluate the efficiency of the proposed method. Finally, sensitivity analysis has been applied, and then the simulation results have been discussed.
\end{abstract}

Keywords: generation expansion planning; teaching-learning based optimization; game theory; carbon emission

\section{Introduction}

It is evident that energy has always been an indispensable part of nations' plans. Several decades ago, it used to supply energy for a limited number of household items chiefly. In parallel with advances in technology and industry, consumption and dependence on electricity have boomed throughout the years. Therefore, having an optimal strategy for the future structure of industries that generate electricity is momentous. For this reason, the generation expansion planning (GEP) problem can be considered to ensure that a fraction of future load demand would be supplied. For years, different optimization techniques have been investigated in order to provide an optimal plan for the expansion of generation [1].

Among related works, Ref. [2] provides a new method with game theory approach in order to regard the electricity market adjacent to the GEP problem with PSO optimization algorithm to provide the optimal plan for expanding the generation and reducing the $\mathrm{CO}_{2}$ gas emission. In [3] Corrected Normal Boundary Intersection to diagnose pareto optimal solutions, a contributory lexico-graphic optimization method is applied to improve the NBI method modeled on a synthetic test system over a 6-year period. Ref. [4] proposes a new hybrid model next to GEP for the case study in Iran to estimate the GEP problem for the long term (2016-2030). Furthermore, it directs at improving the combination of renewable energy 
resources in the network. For mentioned purpose, it uses a hybrid fuzzy analytic network and NSGA-II in two stages, respectively. Finally, it demonstrates the high importance of renewable energy plants in the future power system of Iran. Ref. [5] simultaneously considers the electricity demand forecasting and generation expansion planning to promote the power system planning. In this study, genetic algorithm, artificial immune system, and differential evolution solve the problem during two periods, long-term (12 years) and short-term (6 years). Its main aim is to minimize the cost and environmental effects.

Due to the importance of renewable energies, Ref. [6] introduces a new model for GEP to increase the incorporation of renewable energy resources over the planning. This survey is in the case study of China with considering uncertainties of load and renewable energies. In [7], a new technique is presented for the GEP problem to integrate distributed and centralized generation units. Moreover, this study considers the genetic algorithm to discover the optimal resolution for a combined objective function. Ref. [8] provides a model for expanding the power systems by simulating over the 15-year period. In this study, the applied algorithm to establish the optimal solution is a meta-model assisted evolutionarily. Results of this paper exhibit that it is an efficient approach.

Because of the penetrating the renewable power plants in power systems considering the energy storage systems in networks is necessary [9]. In [10], the GEP problem is considered with hourly variability of the wind and solar power. Ref. [11] introduces a model for GEP that the units of the generation that energy storage systems are considered to diminish the reliability of the power system. In this kind of model, the cost of reliability is calculated by the amount of the lost load and the anticipated energy not supplied in which, a novel linear expected energy not supplied model is employed that is simulated on the IEEE-RTS system to display the efficiency of this new formulation. In [12], different models of GEP combined with renewable energy resources are reviewed. It divides them based on the employed techniques of optimization. The key point about this paper is comparing them with their merits and demerits. Ref. [13] suggests an optimum plan for the generation expansion to lessen the total cost. This goal is obtained by ensuring the power system operates correctly and considering the requisite conditions of integrating renewable energy resources in the power grid (model for thermal-wind-photovoltaic). In [14], the expansion is considered for the transmission and generation problem for an energy hub (electricity and natural gas). The regarded way for this problem in this study is an improved genetic algorithm.

The influence of solar and wind integration and distinct reliability aims is analyzed in [15] for the electricity generation expansion planning. The applied model for expanding generation capacity is national electricity market optimizer (NEMO) through the covariance matrix adaptation evolution strategy (CMA-ES) algorithm considered for all candidates in the case study of Indonesia's Java-Bali. Differential evolution (DE), opposition-based differential evolution (ODE) and self-adaptive differential evolution (SaDE) algorithms are considered in [16] to find the optimized plan for generation expansion of the case study in Indian state Tamil over a 6-year and a 12-year period. The key point about this study is considering the penalty costs on emissions and new technologies for generating the electricity and comparing them in different strategies.

Considering the presence of renewable energy resources for environmental reasons in the future of a system is necessary, in [17], the differential evolution algorithm (DE) is exerted to GEP problem with the wind power plant for different goals.

By considering the unit commitment as one of the most important problems in the operation of power systems, in [18] influence of unit commitment with load and renewable energy unpredictability on the GEP problem is studied. In this study, the regarded method for the GEP problem is a robust model and for unit commitment is a data-driven robust model.

It is obvious that in parallel with the expansion of the generation units, the transmission should be expanded [19]. In [20], the planning of renewable energy resources is considered adjacent to the expansion of the transmission to promote the system's flexibility. 
Mixed-integer linear programming (MILP) model is exerted for finding the optimal answer for this issue. In [21] a mixed-integer linear programming formulation is provided for the generation and transmission expansion planning problem simultaneously, which is resolved by a nested benders decomposition and a tailored benders decomposition algorithm in the case study of Texas.

Due to the consequences of the carbon environment having an optimal plan for the expansion of the generation units is necessary to decrease the amount of carbon. So, in [22], a low carbon model for GEP is introduced. The problem is modelled as a mixed-integer linear programming (MILP) which is resolved through the CPLEX algorithm.

Since climate mitigation has become an important issue throughout the world, in [23], it is considered with a GEP problem which is modelled as a multi-level optimization problem with a risk-averse agent for balancing. In [24], a framework for the GEP problem with the mixed energy system is provided. The problem is solved by formulating a mixedinteger linear programming problem to decrease the cost of the mixed energy system. With increasingly integrating renewable energy resources in the power systems, the importance of their uncertainty increases. Ref. [25] plans generation expansion for stochastic windthermal power plant of which the probabilistic characteristics are considered. In this study, a MILP also is introduced which is solved with the branch-and-cut algorithm. Ref. [26] provides a two-stage nested bilevel model for the GEP problem. Furthermore, a novel algorithm is introduced in order to convert the provided model to a mixed-integer quadratic programming (MIQP) problem.

Having enough information about the different dimensions of the conducted works about the GEP problem for providing a novel technique can be useful. Hence, Ref. [27] carry outs a review about the distinct dimensions of the state-of-the-art generation expansion planning such as the plan for expansion of the transmission, the systems work with gas, interim activities of markets for power, electric automobile and that sort of things. In [28], the GEP problem is considered in the presence of the renewable energy market. In this study, the provided problem is solved by the integration of the Karush-Kuhn-Tucker (KKT) method and the fixed-point iterative algorithm. The uncertainty of renewable energy resources is one of the most important criteria that should be considered. In [29], a twostage robust plan is proposed for generation expansion regarding the probability of the immense amount of wind energy. In this paper, the provided GEP problem is resolved with mixed-integer linear programming (MILP).

The hydropower plant is one of the useful power plants for areas with enough hydropower. In [30], the GEP problem for hydropower is considered in the case study of the Sulawesi power system. Ref. [31] in a multi-objective model for the GEP problem focuses on the operational flexibility in the presence of renewable energy resources. The applied way for solving this problem is the non-dominated sorting genetic algorithm version II (NSGA-II).

Along with advances in technologies in power systems, the appliances and structure of these kinds of systems will change. In [32], the GEP problem is considered with microgrid aggregators. In this study, the applied algorithm to find the best solution is the gravitational search algorithm (GSA).

To create a competitive situation in the GEP problem, different game theory (GT) approaches such as Nash-Cournot (NC), Nash-Bertrand (NB), and bi-level are used. In [33], the Cournot-Bertrand model is applied for the GEP problem and categorizes 12 primary models of this theory. In a similar study [34], a novel bi-level technique is regarded for GT to provide an optimal plan for the generation expansion of the power systems. In [35], a game theoretical approach is considered to provide an optimal plan simultaneously for sub-transmission and generation expansion.

The increasing presence of distributed generation in power systems demands a key point that should be considered in the generation expansion planning problem. This key point is coordination and interaction between the transmission and distribution systems that in [36] GEP problem is regarded with this criterion. Additionally, in [37] is used 
a new way which is called Bayesian network for the dynamic behavior of the system with considering uncertainties of renewable power plants in a multi-objective generation expansion planning decision model regarding permanent development. Because of the changeable output of renewable energy resources, considering flexibility requirements with respect to the power system is an important issue. Ref. [38] introduces a power-based GEP model that improves this issue.

Consequently, significant contributions of this study proposed a novel algorithm and a developed model to solve the GEP problem by a game theory approach. First, we analyzed the GEP problem with a TLBO algorithm that outperformed in the quality of solutions and convergence speed under the condition of our problem and compared the results with previous methods. Next, we have modelled the problem by GT to maximize each power plant's profit. In the end, we considered carbon emission parameters in the NC model, met the peak demand and formulated the government's objective under a unique strategy, namely with the carbon tax and government subsidy. We analyzed the effect of applied regulation on the optimal decisions of the NC model in the GEP problem.

In conclusion, we applied mentioned scenarios regarding the structure of the GEP and government regulations. We comprehensively compared the effects of different governmental carbon and subsidy regulations by sensitivity analysis.

The rest of the paper is organized as follows: Section 2 describes the problem. Section 3 applies the TLBO algorithm to the GEP problem and compares it with other prominent algorithms. In Section 4, the results of the simulation are illustrated, then the results are discussed and analyzed. In the last section, the conclusion is presented.

\section{Problem Description}

\subsection{Generation Expansion Planning}

The GEP problem is one of the most important parts of planning for power systems. It aims to find the best method to expand the power plants with the most reliability and the least cost of the energy required for the customers. So, this plan should determine where, when, and how much capacity for new power plants should be created. In this study, three scenarios have been taken into account to prove the efficiency of the proposed method. In the first scenario, the optimization problem has been solved with respect to governments ${ }^{\prime}$ criteria, and the minimum cost is achieved without regarding a game theory model. In the next scenario, game theory is applied to make a competitive situation for power plants to be able to achieve the maximum profit by providing the optimal strategy over the regarded period. This scenario has been considered without applying any penalty for fossil fuel or subsidy for renewable resources. The last scenario assumes two criteria. The first one is a deterrent factor to declining $\mathrm{CO}_{2}$ generation by fossil-fuel power plants. Second, a factor for the subsidy that government allocate to encouraging the increase in renewable energy resources.

The objective function that should be optimized in the first scenario is considered as:

$$
\begin{gathered}
F_{\text {min }}=\left\{F_{\text {cost }_{\text {gem }}}+F_{\text {cost }_{\text {o\&m }}}+F_{\text {cost }_{\text {inv }}}\right\} \\
F_{\text {inv }}=\sum_{s=1}^{9}\left(\sum_{i=1}^{15}\left(C(i) \times C_{\text {inv }}(i) \times N(i)\left(\frac{1}{(1+r)^{i}}\right)\right)\right) \\
F_{\text {gen }}=\sum_{s=1}^{9}\left(\sum_{i=1}^{15}\left(C(i) \times F(i) \times C_{N}(i) \times T_{U} \times C_{F}\left(\frac{1}{(1+r)^{i}}\right)\right)\right) \\
F_{\text {om }}=\sum_{s=1}^{9}\left(\sum_{i=1}^{15}\left(C(i) \times C_{o m}(i) \times C_{N}(i) \times C_{F}\left(\frac{1}{(1+r)^{i}}\right)\right)\right) \\
i=1,2 \ldots, 15 \quad s=1,2, \ldots 9
\end{gathered}
$$

In these equations, the function that has to be optimized is the $F_{\min }$ formed from $F_{\text {gen }}$ (generation costs), $F_{i n v}$ (investment costs) and $F_{O \mathcal{E} M}$ (operation and maintenance costs). 
It is evident that each kind of unit has to generate electricity in the particular range. The limitations relevant to these generators for objective function are considered with inequality constraints below:

$$
\begin{gathered}
M_{\text {min }}<M(i)<M_{\text {max }} \\
0<U(i)<U_{\text {max }} \\
C_{\text {total }}=\sum_{s=1}^{9}\left(\sum_{i=1}^{15}\left(C(i) \times C_{N}(i)\right)\right) \\
\left(1+M_{\text {min }}\right) \times D_{\text {peak }}(i) \leq C_{\text {total }(i)} \leq\left(1+M_{\text {max }}\right) \times D_{\text {peak }}(i)
\end{gathered}
$$

In these equations, $C_{\text {total }}$ has to be supplied worth of load demand over a year. $M_{\max }$ is the maximum amount that each kind of unit can generate. On the other hand, the lower limit $M_{\min }$ is the slightest fraction of generating electricity by each kind of unit.

\subsection{Game Theory Approach}

As the game theory (GT) has different models like Nash-Cournot (NC), Nash- Bertrand (NB), and Bi-level in order to create a competitive situation among all the power plants or players of the game, this paper has been used the NC model in which all players are reluctant to change their plan to increase their profit. In other words, they would not gain more profit in any other strategies, which means that the selected strategy would be the best one. This condition is called the Nash equilibrium point. In this model, independent system operators (ISO) and power plants are considered as players of the game. ISO is an agent that operates as a player by devoting carbon tax and government subsidy to the generation units.

In this paper, we consider power plants as a series of players which are looking to increase their fuel prices. On the other hand, the government (ISO) is the other side of the game theory that seeks to reduce the price of fuel. In addition, based on the Paris Agreement and the international community's desire for clean energy, we examine the effects of the carbon tax and government subsidy as clean fuel incentives in the other scenario. However, two scenarios that are considered by GT include:

- An investigation of GEP problem using NC model (considering GT) from the point of view of power plants by comparison between them;

- An investigation of GEP problem using NC model (considering GT) from the point of view of power plants with considering carbon tax and government subsidy by comparison between them.

The equations with considering the GT theory are described as:

$$
\begin{gathered}
F_{G T 1}=\left\{F_{\text {cost }_{\text {gem }}}+F_{\text {cost }_{\text {o\&m }}}+F_{\text {cost }_{\text {inv }}}\right\} \\
F_{G T 2}=\left\{F_{\text {cost }_{\text {gem }}}+F_{\text {cost }_{\text {o\&m }}}+F_{\text {cost }_{\text {inv }}}+C_{T}+S_{G}\right\} \\
\mathrm{S}_{G}=\sum_{i=1}^{15}\left(S S \times C \times C_{N}\right) \\
C_{T}=\sum_{i=1}^{15}\left(E T \times C O 2 \times C \times C_{N}\right)
\end{gathered}
$$

For the GT modeling, we used the NC method. Our proposed algorithm has combined the bi-level, NC, and TLBO methods. NC is formulated by:

$$
\begin{gathered}
\operatorname{REV}_{G T}=\sum_{i=1}^{15}\left(E P \times C(i) \times C_{N}\right) \\
\Pi_{G T}=R E V_{G T}-F_{G T}, \quad G T=G T 1, G T 2
\end{gathered}
$$


Here, GT is the number of scenarios in game theory approach.

\section{Optimization Algorithm}

Teaching-Learning-Based Optimization

Teaching-learning-based optimization algorithm (TLBO) is one of the newest smart optimization ways that is inspired by the process of teaching and learning. In TLBO, a mathematical model is considered for learning and teaching. It implements in two phases that lead to the optimization of the related system. Firstly, the best member of the population is chosen as a teacher and captures the average of population toward itself. Then, the new best member is chosen as the best teacher among new student Equation (15). That is the task which a good teacher does in the real world.

$$
X_{\text {new }, i}=X_{o l d, i}+r_{i}\left(M_{n e w}-\left(T_{F} \times M_{i}\right)\right)
$$

In another phase, members of the population try to make progress with each other and expand their knowledge. In this phase, randomly, two learners $X_{i}$ and $X_{i}$ are chosen. If the objective function for $i$ member of the class is less than the objective function of $j$ member, the position for that $i$ member is determined by Equation (16); otherwise, the position for it is determined by Equation (17). In this way, the best answer is found by comparing the objective function for all members in a certain iteration. One of the most important qualities of this algorithm is not depending on parameters, because this algorithm has the lowest number of parameters.

$$
\begin{aligned}
& X_{\text {new }, i}=X_{\text {old }, i}+r_{i}\left(X_{i}-X_{j}\right) \\
& X_{\text {new }, i}=X_{\text {old }, i}+r_{i}\left(X_{j}-X_{i}\right)
\end{aligned}
$$

\section{Simulation and Results}

\subsection{Case Study}

Electric load demand increases in parallel with the advances of technology and escalation in population. It reinforces having a tactical and economic schedule and plans for the future of generation units that want to supply the required energy. In this study, 9 kinds of generation units (centralized and distributed in Figure 1) are considered as the best power plants for the next 15 years to implement the GEP problem in the case study of Iran.

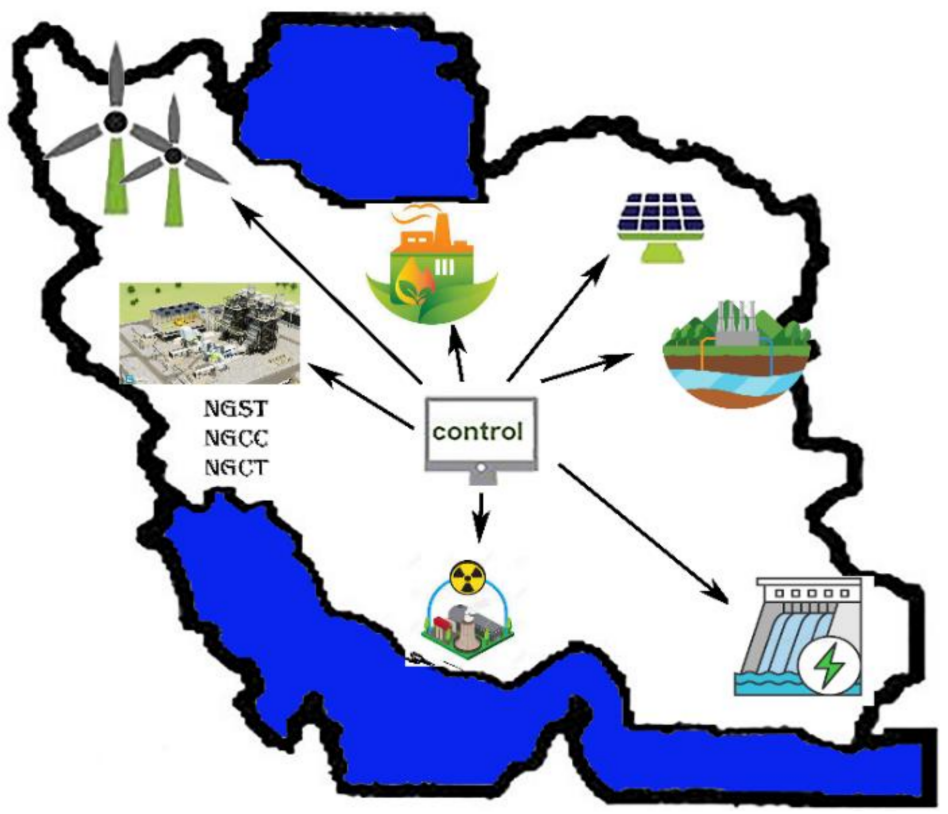

Figure 1. A schematic of regarded power plants in a case study of Iran. 
These regarded power plants include natural gas steam turbine (NGST), natural gas combined cycle (NGCC), natural gas combustion turbine (NGCT), nuclear, hydroelectric, wind, solar, biomass, and geothermal power plants. Furthermore, the TLBO algorithm is regarded to optimize the problem. The peaks of load demand are forecast over 15 years separately. Therefore, GEP is estimated in this period. In this procedure, the total cost, including investment, generation, operation, and maintenance, are contemplated as the objective function. Finally, the results of this problem have been compared with another practical way. Table 1 displays the present number of different kinds of regarded generation units. In this table, the ratio of the non-renewable resource is just over $83 \%$ of total capacity, $14.8 \%$ has been allocated to hydro plants and renewable and nuclear power plants are around $2 \%$ of this capacity. It is evident that fossil-fuel power stations are the main generation units in Iran. All information related to the technological and economic features of considered substitutes are provided in Table 2. In this study, 9 different kinds of generation units are regarded in the case study of Iran in order to go to prove the efficiency of the TLBO algorithm unto another well-known way in the GEP problem.

Table 1. Information of current generation units in Iranian power systems [1].

\begin{tabular}{ccccc}
\hline Type of Unit & $\begin{array}{c}\text { Unit Capacity } \\
\text { (MW) }\end{array}$ & $\begin{array}{c}\text { Number of Each } \\
\text { Unit }\end{array}$ & $\begin{array}{c}\text { Total Installed } \\
\text { Capacity (\%) }\end{array}$ & $\begin{array}{c}\text { Available } \\
\text { Capacity (MW) }\end{array}$ \\
\hline NGST & 160 & 99 & 22.5 & 15,840 \\
NGCC & 300 & 59 & 25.2 & 17,700 \\
NGCT & 160 & 155 & 35.3 & 24,000 \\
Nuclear & 1000 & 1 & 1.4 & 1000 \\
Hydro & 200 & 52 & 14.8 & 10,400 \\
Wind & 100 & 2 & 0.28 & 200 \\
Solar-PV & 100 & 1 & 0.14 & 100 \\
Biomass & 100 & 1 & 0.14 & 100 \\
Geothermal & 50 & 2 & 0.14 & 100 \\
Total & - & - & 100 & $70.24(\mathrm{GW})$ \\
\hline
\end{tabular}

Table 2. Information of current generation units in Iranian power systems [1].

\begin{tabular}{|c|c|c|c|c|c|c|c|c|}
\hline $\begin{array}{c}\text { Type of } \\
\text { Unit }\end{array}$ & $\begin{array}{c}\text { Capacity } \\
\text { (MW) }\end{array}$ & $\begin{array}{c}\text { Max } \\
\text { Num. of } \\
\text { Unit }\end{array}$ & Investment & $\begin{array}{l}\text { Fuel Cost } \\
\text { (\$/MW) }\end{array}$ & $\begin{array}{l}\text { O\&M Cost } \\
\text { (\$/MW) }\end{array}$ & $\begin{array}{l}\text { Capacity } \\
\text { Factor }\end{array}$ & $\begin{array}{l}\text { Theory } \\
\text { Time } \\
\text { Working } \\
\text { (h) }\end{array}$ & $\begin{array}{c}\mathrm{CO}_{2} \\
\text { Generation } \\
\text { Rate (Ton } \\
\mathrm{CO}_{2} / \mathrm{MWh} \text { ) }\end{array}$ \\
\hline NGST & 160 & 5 & $1,250,000$ & 58.82 & 37,150 & 0.77 & 6500 & 0.760 \\
\hline NGCC & 300 & 22 & $1,035,000$ & 47.45 & 14,390 & 0.85 & 7000 & 0.344 \\
\hline NGCT & 160 & 55 & 676,000 & 78.43 & 6700 & 0.85 & 7000 & 0.520 \\
\hline Nuclear & 1000 & 5 & $5,615,000$ & 12.06 & 88,750 & 0.85 & 7000 & 0 \\
\hline Hydro & 200 & 33 & $2,936,000$ & 74 & 85,000 & 0.5 & 7000 & 0 \\
\hline Wind & 100 & 39 & $2,213,000$ & 0 & 28,070 & 0.3 & 3000 & 0 \\
\hline Solar-PV & 100 & 39 & $3,950,000$ & 0 & 16,700 & 0.11 & 2640 & 0 \\
\hline Biomass & 100 & 17 & $4,114,000$ & 41.47 & 100,500 & 0.8 & 8000 & 0 \\
\hline Geothermal & 50 & 55 & $6,243,000$ & 0 & 129,484 & 0.75 & 8000 & 0 \\
\hline
\end{tabular}

The flowchart of the proposed algorithm is shown in Figure 2. It can be described as follows: at first, the initial population is produced by random values, which this population is agents of power plants. In the next stage, the cost of the system is calculated, then they are sorted. Afterwards, this procedure continues in the defined iteration. This iterative procedure is performed until the specific constraints of the system, which are earned from Equations (5), (6) and (8), are confirmed. After establishing the best plan for generation expansion, in the following stage, each kind of unit as a player in the game tries to reach its maximum profit, and it continues until all players reach their optimal strategies. In other words, it will continue to find the Nash equilibrium point. Details of the algorithm parameters have been shown in Table 3. 


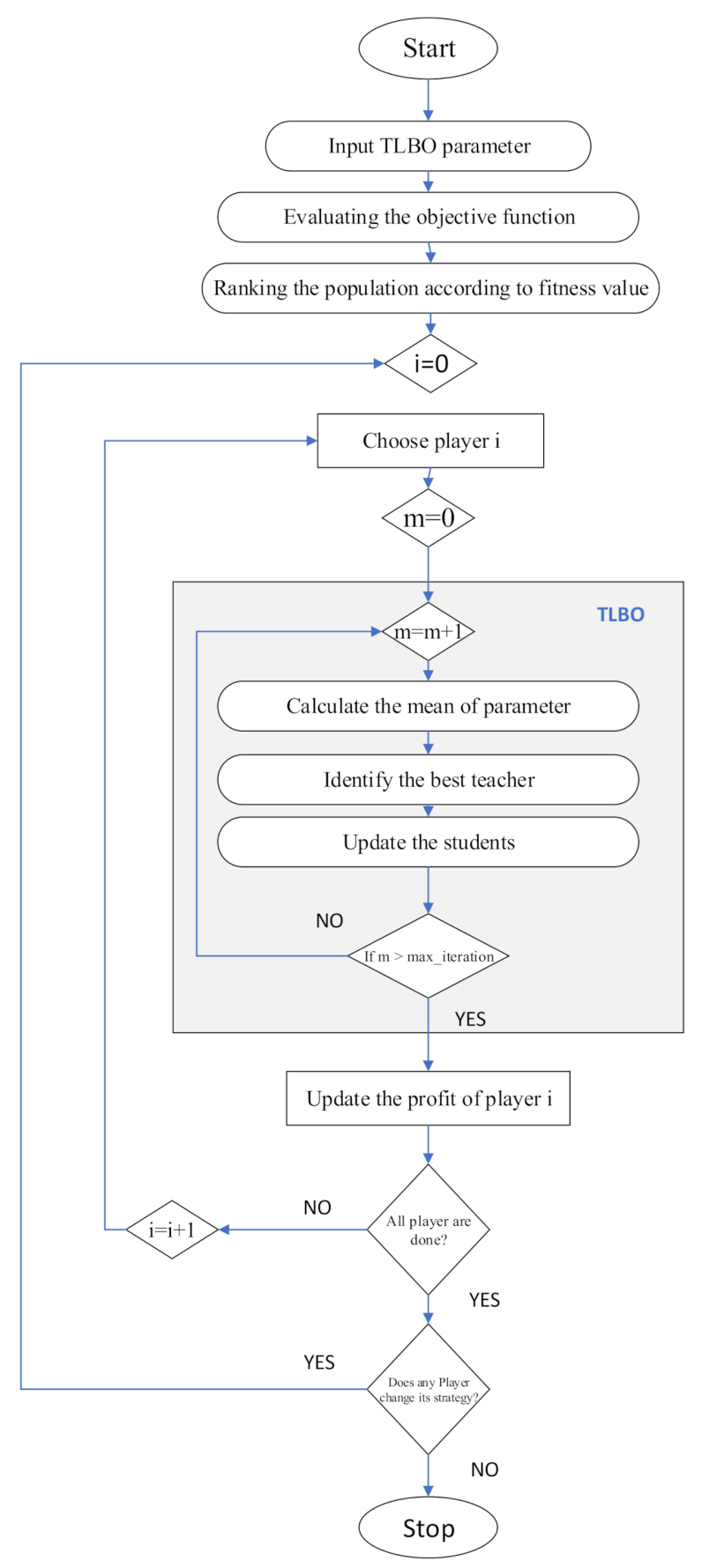

Figure 2. The flowchart of the proposed algorithm.

Table 3. Parameters of the TLBO algorithm.

\begin{tabular}{lc}
\hline \multicolumn{1}{c}{ Parameters } & Value \\
\hline Max number of iterations & 50 \\
Initial population & 200 \\
Random parameter of each new teacher or student & 1 or 2 \\
\hline
\end{tabular}

All simulations were executed on a PC in Rasht, Gilan, Iran with Intel Core i7 CPU @ 3.20 GHz and 32 GB RAM using MATLAB 2021a. 


\subsection{Scenario 1: ISO}

In this scenario, we consider the GEP problem with three optimization methods. The most important point about these algorithms is the simplicity of their implementation. The Particle Swarm Optimization algorithm (PSO) is one of the most important optimization algorithms that is placed in the domain of Swarm Intelligence. In the PSO algorithm, members of the population have contact directly, and they address solving the problem through exchanging information and reminding the last memories [39]. The genetic algorithm (GA) is another well-known and useful one. This algorithm is inspired by the genes in the human body. It utilizes crossover and mutation techniques in order to find the best solution for the problem. From an overall perspective, it can be obtained that the three simulated algorithms in this paper for the GEP problem have their unique answers.

In this scenario, a comparison between these algorithms (PSO and GA) and TLBO has been investigated in a unique case study with the government's viewpoint.

The results in Table 4 reveal that TLBO has found the best solution separately in different costs (operation and maintenance, generation and investment). Additionally, operation and maintenance, and investment costs in GA are better than PSO. However, because of the higher expense of generation by PSO, the second-lowest amount of cost is the solution earned by the GA algorithm followed by the PSO algorithm with only around $15 \mathrm{MW}$ lower. Moreover, the simulation time is not essential because of the long-term prospect in generation expansion planning.

Table 4. Result of simulation.

\begin{tabular}{cccc}
\hline Objective & PSO & GA & TLBO \\
\hline Time (s) & 72.62 & 67.25 & 77.35 \\
Investment cost (MW) & $171,328,530.49$ & $191,666,159.99$ & $123,651,477.57$ \\
O\&M cost (MW) & $15,016,948.47$ & $17,823,268.11$ & $9,888,589.06$ \\
Operation cost (MW) & $147,850,288.42$ & $109,740,447.55$ & $61,050,077.15$ \\
Total cost (MW) & $334,195,767.39$ & $319,229,875.67$ & $194,590,143.79$ \\
\hline
\end{tabular}

In this section, the decline in power plants' total cost by TLBO algorithm has been analyzed and the efficiency of this method on the GEP problem has been discussed.

Turning to Figure 3, in the way that ISO sees, the GEP problem has been considered without the GT approach. It is clear that TLBO has been able to determine the plan for generation expansion over a 15 -year period with minimum costs. In this figure, as expected, by considering the high cost of investment for renewable energy power plants, the number of these kinds of power plants has been more than fossil-fuel power plants over the early years of the period that they can compensate these costs over the following years. In contrast, the number of fossil-fuel power plants with the low investment cost has been more over the late years. Table 5 illustrates the results in the first scenario.

\subsection{Scenario 2: Game Theory without Limitation}

In this scenario, each kind of power plant is considered as a player of the GT that they try to increase their profit by regarding their benefits without any carbon tax and subsidy. This issue can cause investors to be captured to invest more in electricity generation with more profit. These mentioned players are considered as players in a GT model to achieve the Nash equilibrium point. It is the optimum point for all the players that its results can be seen in Figure 4. These results are obtained for players in the Nash equilibrium point which are unwilling to change their strategy. 


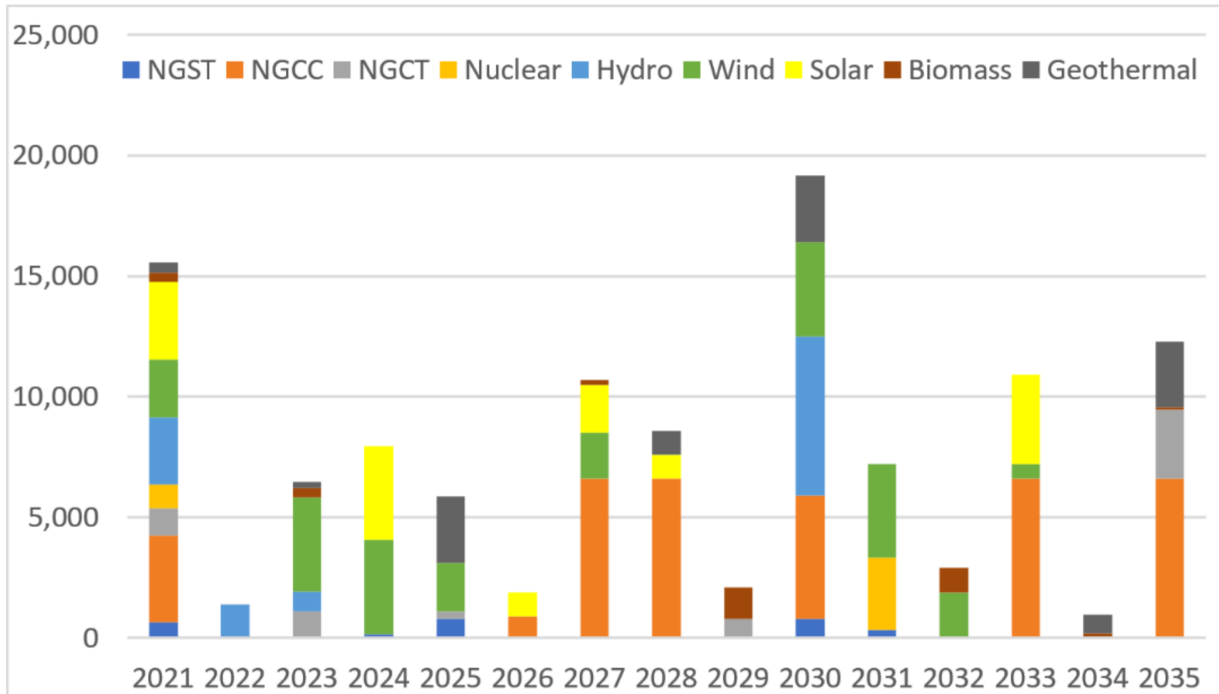

Figure 3. The capacity of additional units in each kind of power plant by the year from ISO viewpoint (MW).

Table 5. Numbers of new units to be added during the planning horizon in TLBO algorithm.

\begin{tabular}{cccccccccc}
\hline Year & NGST & NGCC & NGCT & Nuclear & Hydro & Wind & Solar-Pv & Biomass & Geothermal \\
\hline 1 & 4 & 12 & 7 & 1 & 14 & 24 & 32 & 4 & 8 \\
2 & 0 & 0 & 0 & 0 & 7 & 0 & 0 & 0 & 0 \\
3 & 0 & 0 & 7 & 0 & 4 & 39 & 0 & 4 & 5 \\
4 & 1 & 0 & 0 & 0 & 0 & 39 & 39 & 0 & 0 \\
5 & 5 & 0 & 2 & 0 & 0 & 20 & 0 & 0 & 55 \\
6 & 0 & 3 & 0 & 0 & 0 & 0 & 10 & 0 \\
7 & 0 & 22 & 0 & 0 & 0 & 19 & 20 & 2 & 0 \\
8 & 0 & 22 & 0 & 0 & 0 & 0 & 10 & 0 & 0 \\
9 & 0 & 0 & 5 & 0 & 0 & 0 & 0 & 0 & 0 \\
10 & 5 & 17 & 0 & 0 & 33 & 39 & 0 & 0 & 0 \\
11 & 2 & 0 & 0 & 3 & 0 & 39 & 0 & 0 & 0 \\
12 & 0 & 0 & 0 & 0 & 0 & 19 & 0 & 0 \\
13 & 0 & 22 & 0 & 0 & 0 & 6 & 37 & 0 \\
14 & 0 & 0 & 0 & 0 & 0 & 0 & 0 & 2 \\
15 & 0 & 22 & 18 & 0 & 0 & 0 & 0 & 1 \\
\hline
\end{tabular}

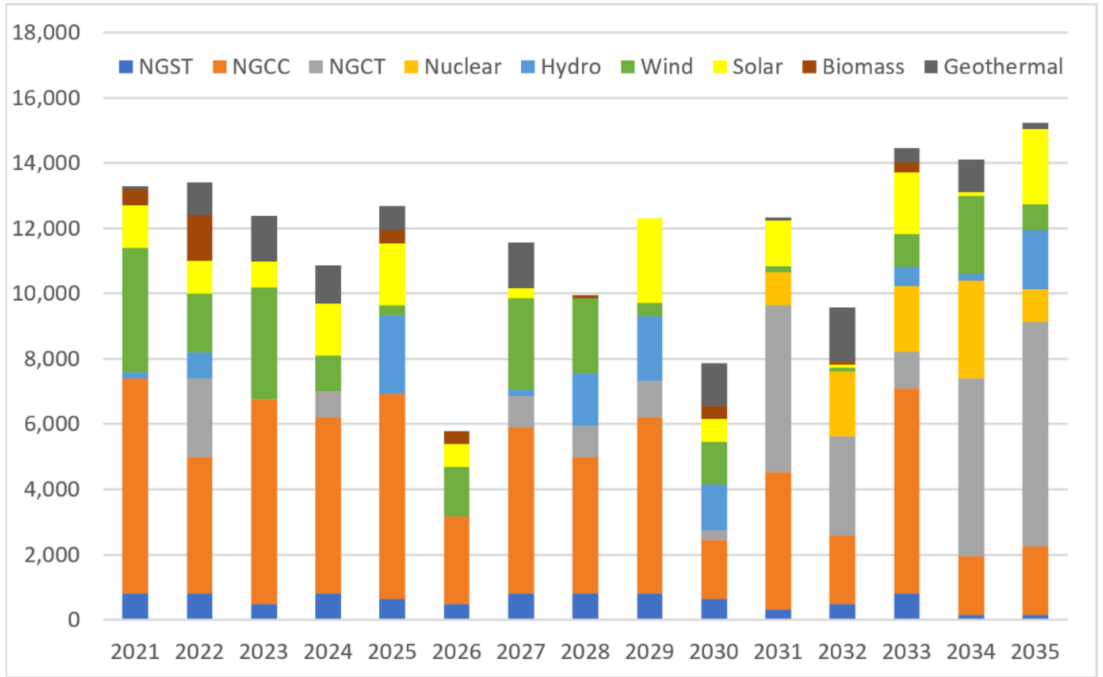

Figure 4. The capacity of additional units in each kind of power plant by the year in scenario 2 (MW). 


\subsection{Scenario 3: Game Theory with Limitation}

In this scenario, as the results can be seen in Figure 5, not only the GT model is considered, but also limitations are imposed on players of the game. The government as an organization imposes tax carbon (\$12) for the fossil-fuel power plants; moreover, it considers an amount of money ( $20 \%$ of the sale price of each MWh) as a subsidy for the investigator to encourage them to build more renewable energy resources.

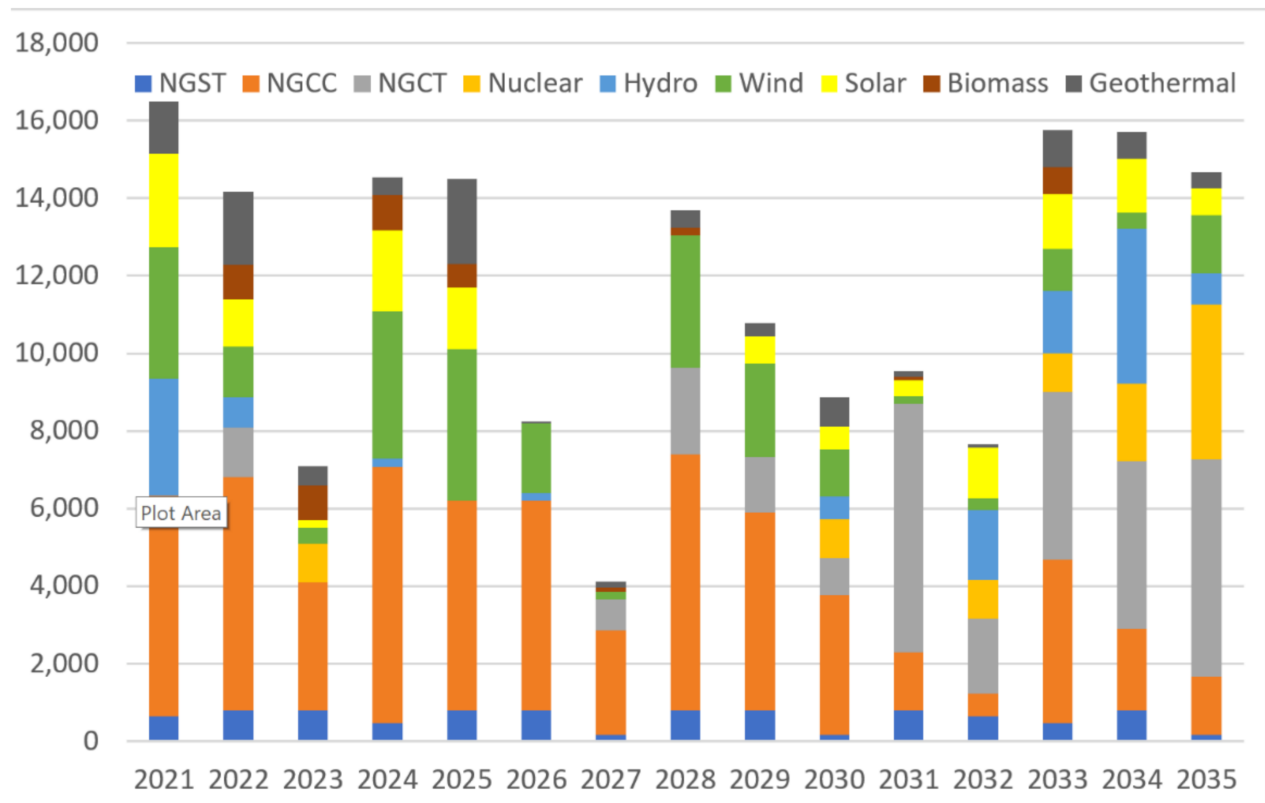

Figure 5. The capacity of additional units in each kind of power plant by the year in scenario 3 by applying the carbon tax and subsidy (MW).

Figure 6 shows the profit for each kind of power plant in scenarios 2 and 3 over a 15-year period in million dollars. As it can be emanated, imposing tax carbon and subsidy makes it better for investors to invest in renewable energy power plants. Namely, building renewable energy power plants can be more persuading. If we consider NGCC as a fossilfuel index, it is obvious that the profit for this kind of power plant after imposing tax carbon has gone down, on the other hand, as a positive point in this figure, this profit has gone up for those kinds of power plants which are renewable such as solar, wind and hydro. These results illustrate not only in terms of financial aspects is profitable, but also this can be helpful with respect to environmental issues.

Figure 7 is the cumulative sum of units' numbers in 2035 (the last year in the considered period in this paper). The regarded unit for this diagram is MW. It is evident that when we implement GT that each kind of power plant wants to maximize their profit, the installed capacity is more than when ISO is considered its profit. As a result, by raising the power of the network, the reliability of the power system will increase. Moreover, in this way, social welfare will grow. Furthermore, this method can be profitable in terms of the electricity market. Additionally, these results illustrate that, in scenario 3, the capacity of renewable energy power plants like hydro has increased, while the capacity of NGCC as a fossil-fuel power plant has decreased. 


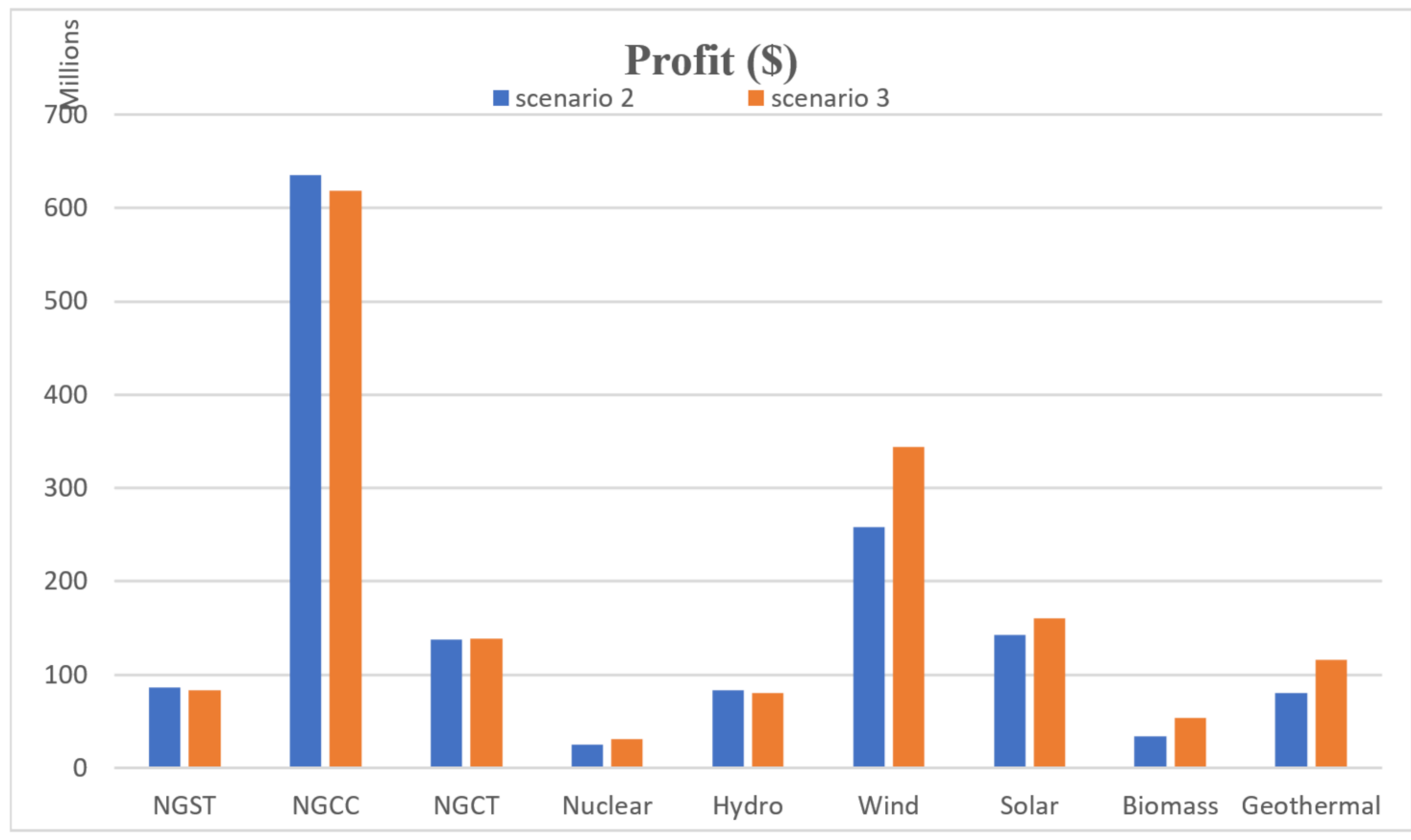

Figure 6. The profit of each power plant in strategy 2 and 3 in million dollars.

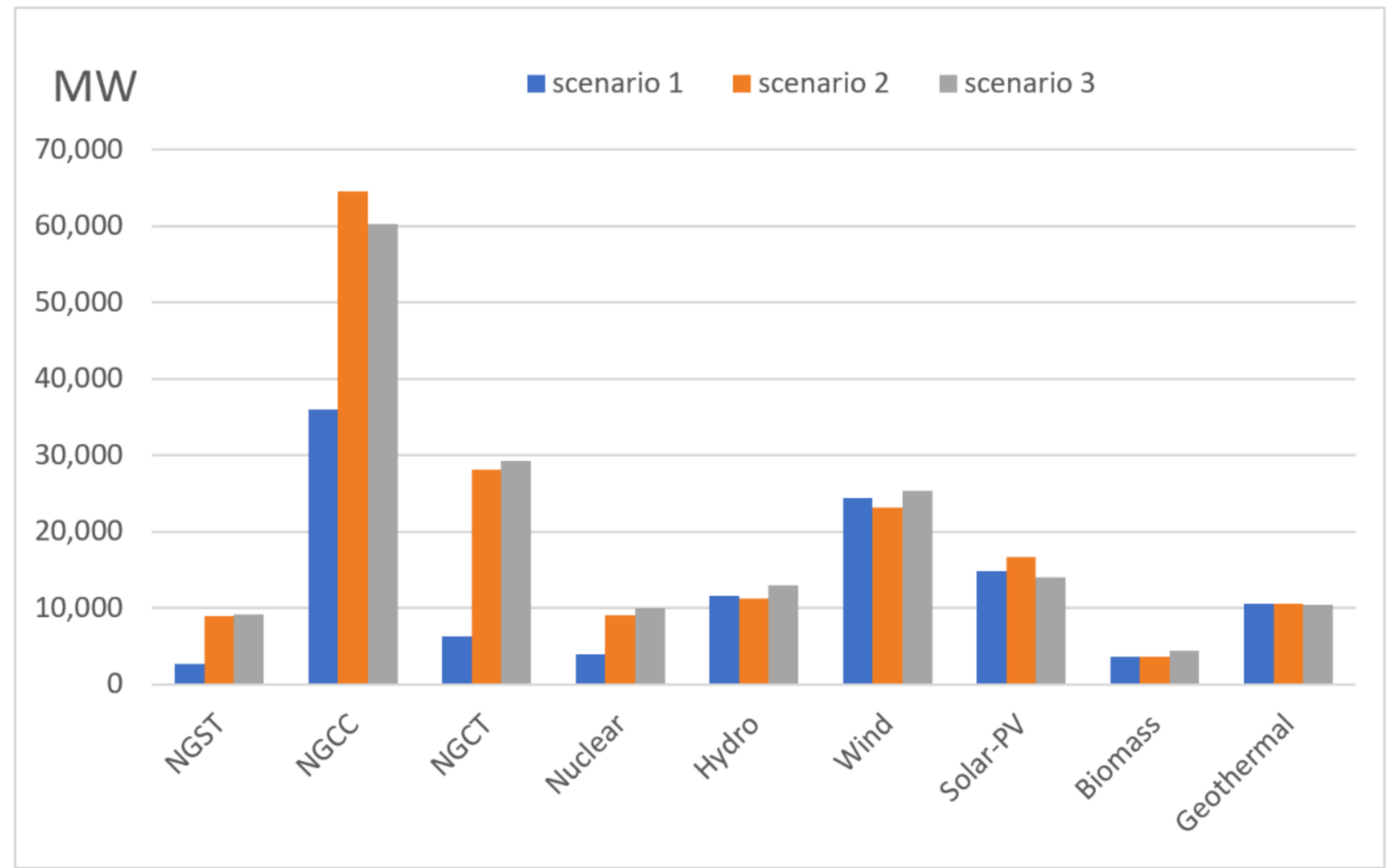

Figure 7. The total cumulative capacity of each power plant in all scenarios in 2035.

\subsection{Sensitivity Analysis}

This section analyzes the problem by considering the different proportions of subsidy and carbon tax for the power plants. Given Figure 8, it can be emanated that after imposing the subsidy in the amount of 0,20 and 50 percent of the whole subsidy for the renewable energy power plants such as wind, solar, geothermal and biomass, the profit has marginally increased. On the other hand, fossil-fuel power plants' profit such as NGCT or NGCC has declined. As can be discerned from Figure 9, the different amounts of emission tax have been considered. 


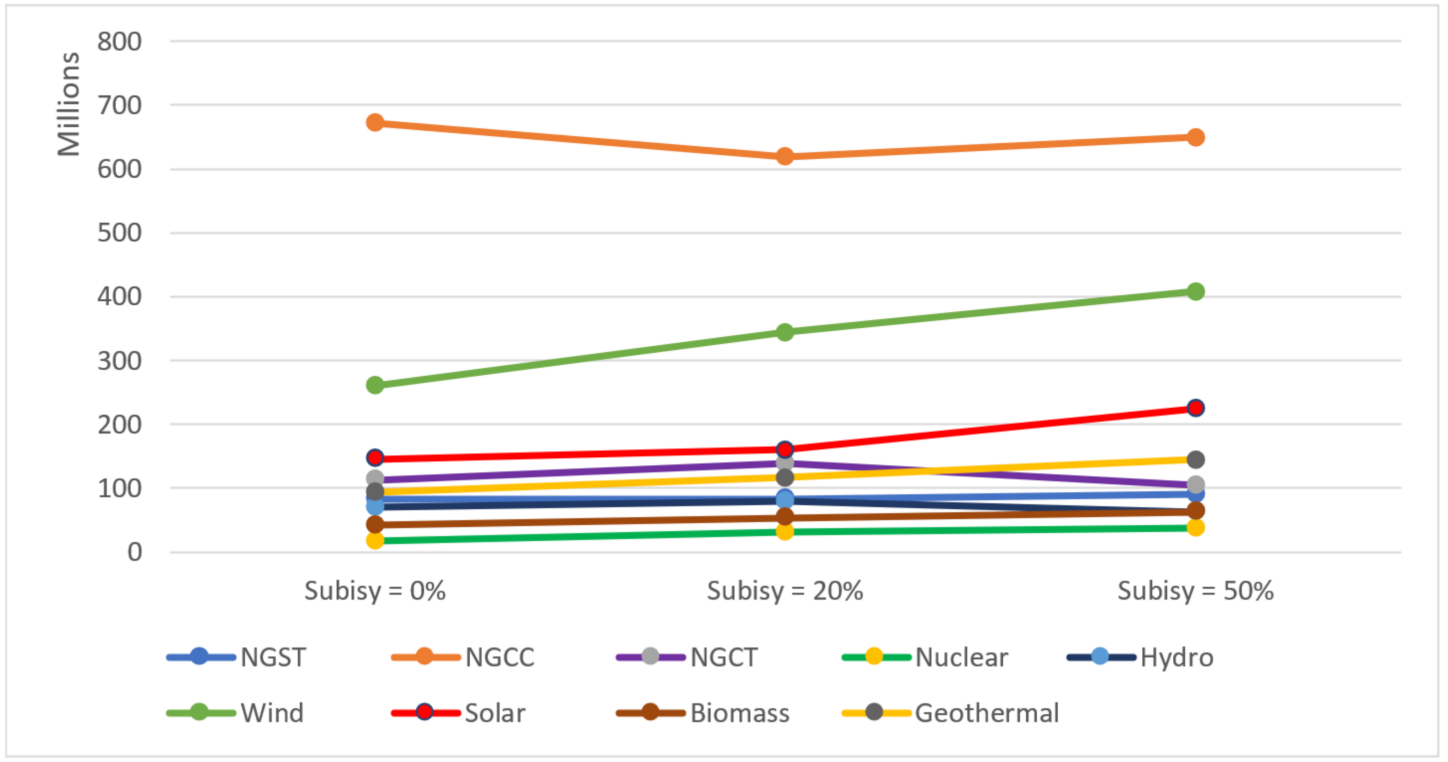

Figure 8. Sensitivity analysis of government subsidy value by power plants profit (Million \$).

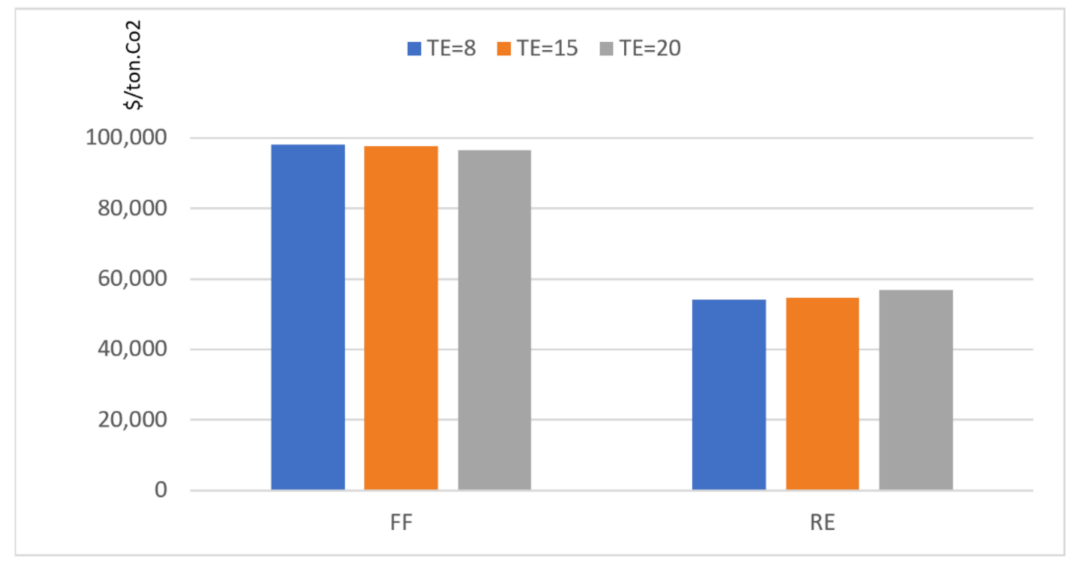

Figure 9. Sensitivity analysis of carbon tax value by fossil fuel (FF) and renewable energy (RE) power plants profit (\$/ton $\left.\cdot \mathrm{CO}_{2}\right)$.

The results related to fossil-fuel power plants illustrate by increasing the emission tax, the capacities of fossil-fuel power plants have decreased. Whereas this tax has caused a rise in the capacity of renewable energy power plants. Indeed, the increase in emission tax and government subsidy not only cannot ensure the decline of greenhouse gases, but also can remove the competitive situation among players. Moreover, it can lead to not supplying the load demand. Therefore, considering GT with novel optimization algorithms demands the Nash equilibrium point in order to achieve green expansion planning.

\section{Conclusions}

From what has been discussed, it can be drawn that the GEP problem is one of the practical and economical ways to achieve planning goals such as distinct costs of the power plants and decreasing pollution generated by fossil-fuel power plants. Hence, organizing an optimal strategy for the GEP problem is crucial for the power systems. Namely, choosing the optimization algorithm in the GEP problem is determinant. In this paper, the TLBO algorithm has been compared with GA and PSO, and results proved the efficiency of this algorithm in the problem. Moreover, in order to create a competitive situation among power plants to increase their profit, the GT approach was applied. This approach showed 
more penetration of the renewable energy power plants, which declares the efficiency of this method.

Author Contributions: Software, conceptualization, formal analysis, methodology, writing —original draft preparation, investigation, data curation, S.H.J., H.Y. and R.H.; validation, resources, writingreview and editing, supervision, project administration, M.D., A.N., M.K. and T.S. All authors have read and agreed to the published version of the manuscript.

Funding: This research received no external funding.

Informed Consent Statement: Informed consent was obtained from all subjects involved in the study.

Data Availability Statement: All materials have been gathered from second and forth reference of this paper.

Conflicts of Interest: The authors declare no conflict of interest.

\section{Nomenclature}

Parameters
$C$
$C_{i n v}$
$N$
$F$
$C_{N}$
$T_{U}$
$C_{F}$
$C_{\text {total }}$
$M_{\text {max }}$
$M_{\min }$
$U_{\text {max }}$
$C_{o m}$
$E T$
$S S$
$E P$
$R E V$
$i$
$\mathrm{~S}$

\section{Description}

The amount of every kind of generation unit

The cost of each unit's investment (\$/MW)

The number of every kind of considered units

The cost proportion of generation variable of every unit (\$/MWh)

The cumulative sum of units' number

Working time of considered units (hour)

The coefficient of capacity of every unit

Total capacity of electricity generation

The highest amount of reserve margin

The lowest amount of reserve margin

The maximum number of units

The cost of operating and maintenance of every unit (\$/MW)

The emission cost of $\mathrm{CO}_{2}$ ( $\$ /$ tonCO $\mathrm{C}_{2}$ year)

The amount of subsidy that government allocate to power plants (\$/MWh)

Energy price

The revenue from selling the electric energy of each player

The number of years that has been considered

The number of generation units that has been regarded

\section{References}

1. Dehghani, M.; Taghipour, M.; Gougheri, S.S.; Nikoofard, A.; Gharehpetian, G.B.; Khosravy, M. A Deep Learning-Based Approach for Generation Expansion Planning Considering Power Plants Lifetime. Energies 2021, 14, 8035. [CrossRef]

2. Haghighi, R.; Yektamoghadam, H.; Dehghani, M.; Nikoofard, A. Generation expansion planning using game theory approach to reduce carbon emission: A case study of Iran. Comput. Ind. Eng. 2021, 162, 107713. [CrossRef]

3. Aghaei, J.; Akbari, M.A.; Roosta, A.; Baharvandi, A. Multiobjective generation expansion planning considering power system adequacy. Electr. Power Syst. Res. 2013, 102, 8-19. [CrossRef]

4. Noorollahi, E.; Fadaia, D.; Ghodsipour, S.H.; Shirazi, M.A. Developing a new optimization framework for power generation expansion planning with the inclusion of renewable energy-A case study of Iran. J. Renew. Sustain. Energy 2017, 9, 015901. [CrossRef]

5. Amosedinakaran, S.; Mala, K.; Bhuvanesh, A.; Kannan, S.; Pandiyan, M.K. Generation Expansion Planning for a Real-world Power System: Aiming Towards Cost and Environmental Emission Minimization by Penetrating Huge Renewable Energy Sources. J. Electr. Eng. Technol. 2021, 16, 2835-2846. [CrossRef]

6. Li, Q.; Wang, J.; Zhang, Y.; Fan, Y.; Bao, G.; Wang, X. Multi-period generation expansion planning for sustainable power systems to maximize the utilization of renewable energy sources. Sustainability 2020, 12, 1083. [CrossRef]

7. Abushamah, H.A.S.; Haghifam, M.; Bolandi, T.G. A novel approach for distributed generation expansion planning considering its added value compared with centralized generation expansion. Sustain. Energy Grids Netw. 2021, 25, 100417. [CrossRef]

8. Vrionis, C.; Tsalavoutis, V.; Tolis, A. A Generation Expansion Planning model for integrating high shares of renewable energy: A Meta-Model Assisted Evolutionary Algorithm approach. Appl. Energy 2020, 259, 114085. [CrossRef]

9. Diewvilai, R.; Audomvongseree, K. Generation Expansion Planning with Energy Storage Systems Considering Renewable Energy Generation Profiles and Full-Year Hourly Power Balance Constraints. Energies 2021, 14, 5733. [CrossRef] 
10. Park, H. Generation capacity expansion planning considering hourly dynamics of renewable resources. Energies 2020, $13,5626$. [CrossRef]

11. Sun, D.; Zheng, Z.; Liu, S.; Wang, M.; Sun, Y.; Liu, D. Generation expansion planning considering efficient linear EENS formulation. Glob. Energy Interconnect. 2021, 4, 273-284. [CrossRef]

12. Dagoumas, A.S.; Koltsaklis, N.E. Review of models for integrating renewable energy in the generation expansion planning. Appl. Energy 2019, 242, 1573-1587. [CrossRef]

13. Li, Y.; Dai, M.; Hao, S.; Qiu, G.; Li, G.; Xiao, G.; Liu, D. Optimal generation expansion planning model of a combined thermalwind-PV power system considering multiple boundary conditions: A case study in Xinjiang, China. Energy Rep. 2021, 7, 515-522. [CrossRef]

14. Malakoti-Moghadam, M.; Askarzadeh, A.; Rashidinejad, M. Transmission and generation expansion planning of energy hub by an improved genetic algorithm. Energy Sources Part A Recovery Util. Environ. Eff. 2019, 41, 3112-3126. [CrossRef]

15. Tanoto, Y.; MacGill, I.; Bruce, A.; Haghdadi, N. Impact of high solar and wind penetrations and different reliability targets on dynamic operating reserves in electricity generation expansion planning. Electr. J. 2021, 34, 106934. [CrossRef]

16. Bhuvanesh, A.; Jaya Christa, S.T.; Kannan, S.; Karuppasamy Pandiyan, M.; Gangatharan, K. Application of optimization algorithms to generation expansion planning problem. J. Intell. Fuzzy Syst. 2018, 35, 1387-1398. [CrossRef]

17. Ramkumar, A.; Rajesh, K. Generation Expansion Planning with Wind Power Plant Using DE Algorithm. Available online: https:/ / www.sciencedirect.com/science/article/pii/S2214785321044783 (accessed on 15 December 2021).

18. Abdalla, O.H.; Adma, M.A.A.; Ahmed, A.S. Generation expansion planning considering unit commitment constraints and data-driven robust optimization under uncertainties. Int. Trans. Electr. Energy Syst. 2021, 31, e12878. [CrossRef]

19. Hinojosa, V.H.; Sepúlveda, J. Solving the Stochastic Generation and Transmission Capacity Planning Problem Applied to Large-Scale Power Systems Using Generalized Shift-Factors. Energies 2020, 13, 3327. [CrossRef]

20. Ansari, M.R.; Pirouzi, S.; Kazemi, M.; Naderipour, A.; Benbouzid, M. Renewable Generation and Transmission Expansion Planning Coordination with Energy Storage System: A Flexibility Point of View. Appl. Sci. 2021, 11, 3303. [CrossRef]

21. Li, C.; Conejo, A.J.; Liu, P.; Omell, B.P.; Siirola, J.D.; Grossmann, I.E. Mixed-integer linear programming models and algorithms for generation and transmission expansion planning of power systems. Eur. J. Oper. Res. 2022, 297, 1071-1082. [CrossRef]

22. Pourmoosavi, M.-A.; Amraee, T. Low carbon generation expansion planning with carbon capture technology and coal phase-out under renewable integration. Int. J. Electr. Power Energy Syst. 2021, 128, 106715. [CrossRef]

23. Kim, D.; Ryu, H.; Lee, J.; Kim, K.K. Balancing risk: Generation expansion planning under climate mitigation scenarios. Eur. J. Oper. Res. 2022, 297, 665-679. [CrossRef]

24. Ko, W.; Kim, J. Generation expansion planning model for integrated energy system considering feasible operation region and generation efficiency of combined heat and power. Energies 2019, 12, 226. [CrossRef]

25. Wang, Q.; Luo, X.; Ma, H.; Gong, N. Multi-stage stochastic wind-thermal generation expansion planning with probabilistic reliability criteria. IET Gener. Transm. Distrib. 2021, 16, 517-534. [CrossRef]

26. Cong, H.; Wang, X.; Jiang, C. Two-stage nested bilevel model for generation expansion planning in combined electricity and gas markets. IET Gener. Transm. Distrib. 2019, 13, 3443-3454. [CrossRef]

27. Koltsaklis, N.E.; Dagoumas, A.S. State-of-the-art generation expansion planning: A review. Appl. Energy 2018, 230, 563-589. [CrossRef]

28. Nguyen, H.T.; Felder, F.A. Generation expansion planning with renewable energy credit markets: A bilevel programming approach. Appl. Energy 2020, 276, 115472. [CrossRef]

29. Abdalla, O.H.; Smieee, L.; Adma, M.A.A.; Ahmed, A.S. Two-stage robust generation expansion planning considering long- and short-term uncertainties of high share wind energy. Electr. Power Syst. Res. 2020, 189, 106618. [CrossRef]

30. Putranto, L.M. Generation expansion planning for high-potential hydropower resources: The case of the Sulawesi electricity system. Int. J. Sustain. Energy Plan. Manag. 2020, 28, 37-52.

31. Oree, V.; Hassen, S.Z.S.; Fleming, P.J. A multi-objective framework for long-term generation expansion planning with variable renewables. Appl. Energy 2019, 253, 113589. [CrossRef]

32. Sardou, I.G.; Azad-Farsani, E. Network expansion planning with microgrid aggregators under uncertainty. IET Gener. Transm. Distrib. 2018, 12, 2105-2114. [CrossRef]

33. Tremblay, C.H.; Victor, J.T. Oligopoly games and the Cournot-Bertrand model: A survey. J. Econ. Surv. 2019, 33, 1555-1577. [CrossRef]

34. Akbari, T.; Moghaddam, S.Z. Coordinated scheme for expansion planning of distribution networks: A bilevel game approach. IET Gener. Transm. Distrib. 2020, 14, 2839-2846. [CrossRef]

35. Navidi, M.; Tafreshi, S.M.M.; Anvari-Moghaddam, A. A game theoretical approach for sub-transmission and generation expansion planning utilizing multi-regional energy systems. Int. J. Electr. Power Energy Syst. 2020, 118, 105758. [CrossRef]

36. Gregorio, M.; Contreras, J.; Arroyo, J.M.; de la Nieta, A.S.; Gibescu, M. Integrated Transmission and Distribution System Expansion Planning under Uncertainty. IEEE Trans. Smart Grid 2021, 12, 4113-4125.

37. Kong, X.; Yao, J.; Wang, X. Generation Expansion Planning Based on Dynamic Bayesian Network Considering the Uncertainty of Renewable Energy Resources. Energies 2019, 12, 2492. [CrossRef] 
38. Tejada-Arango, D.A.; Morales-España, G.; Wogrin, S.; Centeno, E. Power-based generation expansion planning for flexibility requirements. IEEE Trans. Power Syst. 2019, 35, 2012-2023. [CrossRef]

39. Dehghani, M.; Bagheri, M.; Nurmanova, V.; Taghipour, M.; Karimyan, P.; Gharehpetian, G.B.; Abedi, M. An Improved PSOGA based fuzzy controller of STATCOM for cascaded induction motors of drilling system. In Proceedings of the 2020 IEEE International Conference on Environment and Electrical Engineering and 2020 IEEE Industrial and Commercial Power Systems Europe (EEEIC/I\&CPS Europe), Madrid, Spain, 9-12 June 2020; IEEE: New York, NY, USA, 2020. 